\title{
PRELIMINARY RESULTS OF SIMULTANEOUS RECORDING OF AURORAL AND GEOMAGNETIC PULSATIONS AT THE ISTP SB RAS STATION ISTOK
}

\author{
A.B. Beletskii \\ Institute of Solar-Terrestrial Physics SB RAS, \\ Irkutsk, Russia, beletsky@iszf.irk.ru

\section{R.A. Rakhmatulin} \\ Institute of Solar-Terrestrial Physics SB RAS, \\ Irkutsk,Russia,rav@mail.isz.irk.ru
}

\section{T.Ye. Syrenova}

Institute of Solar-Terrestrial Physics SB RAS, Irkutsk,Russia,angata@mail.iszf.irk.ru

\section{R.V. Vasilev}

Institute of Solar-Terrestrial Physics SB RAS, Irkutsk, Russia,roman_vasilyev@mail.iszf.irk.ru

\section{A.V. Mikhalev}

Institute of Solar-Terrestrial Physics SB RAS, Irkutsk,Russia,mikhalev@mail.iszf.irk.ru

\author{
A.Yu. Pashinin \\ Institute of Solar-Terrestrial Physics SB RAS, \\ Irkutsk,Russia,pash@mail.iszf.irk.ru \\ K. Shiokawa \\ Institute for Space-Earth Environmental Research, \\ Nagoya University, \\ Nagoya, Japan, shiokawa@isee.nagoya-u.ac.jp \\ N. Nishitani \\ Institute for Space-Earth Environmental Research, \\ Nagoya University, \\ Nagoya, Japan, nisitani@isee.nagoya-u.ac.jp
}

\begin{abstract}
The paper presents the results on first synchronous observations of variations in auroral luminosity and geomagnetic field, made with high temporal resolution at the ISTP SB RAS high-latitude station Istok $\left(70^{\circ} \mathrm{N}, 88^{\circ} \mathrm{E}\right)$ in September-December 2018. Auroras were recorded with all-sky camera, pulsations in the auroras were recorded by a photometer in four spectral ranges with silicon photomultipliers. Continuous monitoring of geomagnetic pulsations was performed using a LEMI-30 three-component induction magnetometer.

Both synchronous bursts of auroras and magnetic field pulsations, as well as disturbances of auroras, not accompanied by disturbances in the geomagnetic field, were observed. We note that the photometer clearly recorded short-period ( $20 \mathrm{~min})$ variations in auroral
\end{abstract}

\section{INTRODUCTION}

Currently, there are many unresolved problems concerning the processes occurring in the auroral ionosphere. Studying the fast processes occurring in the auroral atmosphere requires experimental data with high temporal resolution. To obtain high-quality results, one needs a large amount of experimental data, including those obtained at spaced apart points. This allows us to trace propagation of disturbances of various nature. A large amount of data provides monitoring measurements which need stations with an automatic operation mode in polar conditions.

Geomagnetic pulsations of all types, both regular and irregular, are known to be accompanied by similar pulsations of the auroral intensity, i.e. auroral pulsations [Roldugin, Roldugin, 2017]. Synchronous registration of auroral and geomagnetic pulsations is therefore interesting. This registration makes it possible to trace the dependence of precipitation of energetic particles and generation of geomagnetic pulsations. For example, luminosity. At the same time, some instability of the photometer signal level occurred at sufficiently long time intervals.

In the photometer data, there are powerful signal bursts, probably of a hardware nature. Nevertheless, the temporary distribution analysis of the registration moments (registration frequency) of signal bursts indicates the possible dependence of the burst registration frequency on the geomagnetic activity level.

Keywords: auroral atmosphere, magnetic pulsations, photometer, induction magnetometer. 
auroras of about $10 \mathrm{~Hz}$.

Also of interest is the study of OFs lasting from units of milliseconds to several seconds. Similar phenomena were first discovered at high latitudes at $557.7 \mathrm{~nm}$ and $630.0 \mathrm{~nm}$ when observing auroras [Nadubovich, 1970; Kuzakova, 1972]. Ermilov and Mikhalev [1989] noted that the OFs with the above characteristics, recorded initially in the auroral zone [Nadubovich, 1970], later in the subauroral zone [Korobtsova, 1981], and then at midlatitudes, are the same geophysical phenomenon. In some cases, emission bursts were accompanied by integral radiation bursts recorded by an all-sky electrophotometer; in other cases, a signal increase was observed only with one of the instruments. In part, this may be due to the unequal sensitivity of the electrophotometer in different parts of the spectrum, however, one cannot exclude that the emissions on the records can simply be interference [Kuzakova, 1972].

As noted above, studying such processes requires equipment that allows the automatic registration of auroral and geomagnetic pulsations with high temporal resolution. In 2018, two experimental campaigns were conducted at the station Istok using such equipment. The station Istok is located $\sim 70 \mathrm{~km}$ north of Norilsk at the geographic coordinates of $70^{\circ} 02^{\prime} \mathrm{N} .88^{\circ} 02^{\prime} \mathrm{E}$. (The geomagnetic coordinates of the station are $66^{\circ} 10^{\prime} \mathrm{N}$, $162^{\circ} 45^{\prime}$ E, [http://sdnet.thayer.dartmouth.edu/aacgm/ aacgm_calc.php\#AACGM]).

The work of the Istok station was resumed in 2013 after conservation in the 1990s. To this end, in 2013, an autonomous monitoring and measuring station was delivered to the Istok station, which enables experimental studies (including optical methods) of the upper atmosphere and Earth's ionosphere in an automatic mode [Beletsky et al., 2016]. The station Istok makes automatic monitoring measurements, as well as conducts specialized experimental campaigns with the participation of ISTP SB RAS researchers. In connection with the working conditions at the station, equipment is required that is capable of operating for a sufficiently long time in a fully automatic mode. One of the goals of the study is to test the applicability of a photometer with radiation detectors based on silicon photomultipliers for recording auroral pulsations with high temporal resolution, similar to the temporal resolution of an induction magnetometer.

\section{EXPERIMENTAL EQUIPMENT AND METHODS}

During synchronous measurements of geomagnetic and auroral pulsations, a set of instruments from the station Istok was used, including a three-component induction Lemi-30 magnetometer $(\Delta f=0-30 \mathrm{~Hz})$, a spectrometer with a spectral range from 400 to $700 \mathrm{~nm}$, and wide-angle cameras for various spectral ranges. The main optical instruments, whose data are used in this study, involve: an all-sky camera of the PWING project [Shiokawa et al., 2017] and a photometer with radiation receivers based on silicon photomultipliers. The all-sky camera has the following characteristics. Camera model: Keo Sentry 3". Matrix type: Cooled-CCD camera Ha- mamatsu C11090-22B. Matrix resolution: 1024×1024. Spectral filters: i) $557.7 \mathrm{~nm}(\mathrm{OI})$, ii) $630.0 \mathrm{~nm}(\mathrm{OI})$, iii) spectral $\mathrm{OH}$ band $(720-1000 \mathrm{~nm})$, iv) $486.1 \mathrm{~nm}(\mathrm{H} \beta)$, v) $572.5 \mathrm{~nm}$. Temporal resolution depending on the filter: 1) Filter 1, 2, and 4: $\sim 90 \mathrm{~s}$; 2) Filter 3, 5: 10 min. Field of view: $180^{\circ}$. Angular resolution: $\sim 0.35^{\circ}$. Spatial resolution: more than $0.7 \mathrm{~km}$ at an altitude of $100 \mathrm{~km}$.

The photometer operates in four spectral ranges. The field of view of a single spectral channel is $\sim 30 \mathrm{~g}$. The radiation receiver for each spectral channel comprises four independent elements, which enables us to obtain data on the spatial distribution of the detected radiation (Figure 1). The photometer is directed at the zenith and allows one to record a signal with a $10 \mathrm{~ms}$ time resolution. To isolate the spectral ranges, we have used interference filters with transmission band centers of $391.4 \mathrm{~nm}$, $427.8 \mathrm{~nm}, 557.7 \mathrm{~nm}$, and $630 \mathrm{~nm}$, and a half-width of $10 \mathrm{~nm}$. Photometer Sensors - ArrayJ-60035-4P-EVB (Large Area Silicon Photomultiplier). The maximum sensitivity of the sensor (Photon Detection Efficiency (PDE)) at a $420 \mathrm{~nm}$ wavelength exceeds $50 \%$. PDE for $557.7 \mathrm{~nm}$ and $630 \mathrm{~nm}$ are $\sim 27 \%$ and $\sim 17 \%$ respectively.

The following algorithm is used for the photometer operation. Recording is at the $200 \mathrm{kHz}$ sampling frequency. Data are recorded in 10-s blocks. The interval between the 10-s measurement units is $\sim 2$ s. Being extensive, the obtained data are preprocessed simultaneously with the measurements. After the preprocessing, we receive summarized data with a $10 \mathrm{~ms}$ time resolution. In this case, the original data $(200 \mathrm{kHz})$ are stored as images (see Figure 6). During automatic data processing, if the signal is exceeded by more than 3 standard deviations from the average signal, an event (signal surge) is recorded.

\section{OBSERVATIONAL DATA}

Before presenting the results of the study conducted, it is worth noting that the periods of the experiments correspond to solar minimum. At that time, the so-called areas of corotational interaction can be observed in the interplanetary space, i.e. the interactions between slow

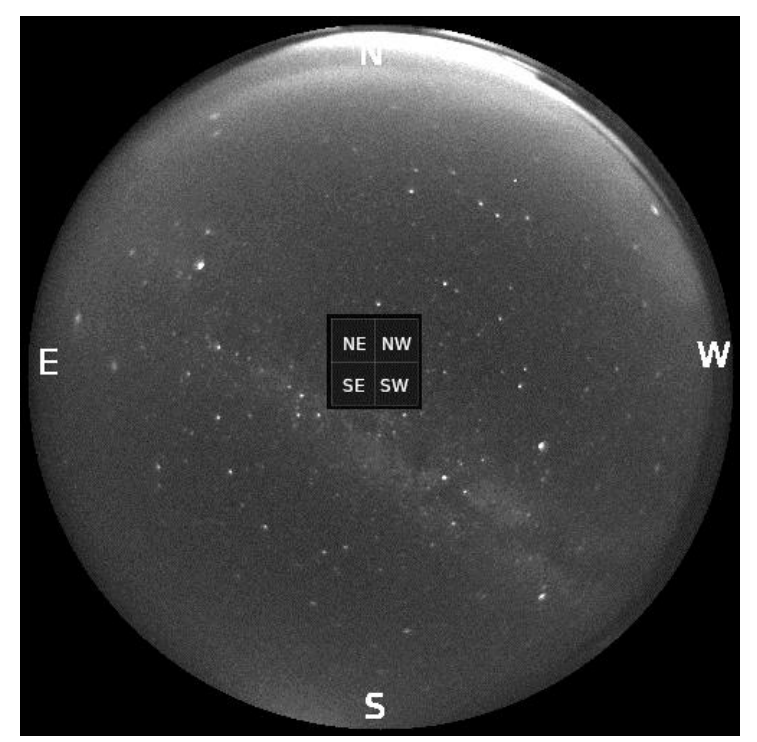

Figure 1. Photometer field of view for four spatial channels 
and fast solar wind currents characteristic of such a solar activity period. The interaction between a fast flow and a slow flow leads to the formation of the compression region (in the English-language literature, it is termed the Corotating Interaction Region - CIR) [Richardson, 2004]. By compressing and changing the direction of plasma motion, a geoeffective component of the interplanetary magnetic field can be formed, thus stimulating geomagnetic activity including magnetic storms and substorms. The periods of such magnetospheric activity feature the unconventional development of geophysical phenomena accompanying this disturbance, the study of which is particularly interesting. Research experiments of geophysical phenomena accompanying the development of magnetospheric disturbances during such periods of solar activity are important and relevant, because they allow us to reveal the causal relationships between these complex events.

\section{SYNCHRONOUS OBSERVATIONS OF AURORAL AND GEOMAGNETIC VARIATIONS}

The first simultaneous observations of luminosity variations in the optical range and geomagnetic pulsations at the ISTP SB RAS high-latitude station Istok using the complex of geophysical equipment described above were conducted in September 2018.
The weather conditions during the pilot campaign enabled only a short ( $\sim 1$ hour) measurement session in September 2018. The evolution of magnetic disturbances in the observation region (Istok) was monitored from observatories of the Russian Arctic sector (Tiksi, Dikson, Amderma). The magnetic field disturbances did not exceed 200-300 nT. $\left(K_{\mathrm{p}}=3, D s t=0\right.$ nT $)$. The September 8, 2018 synchronous observations of auroral and geomagnetic pulsations during the evolution of a weak magnetic disturbance have revealed the following (Figure 2).

There is a fairly good coincidence of the signals obtained with different instruments. Herewith, the time resolution of the photometer $(10 \mathrm{~ms})$ is much higher than that of the all-sky camera ( $90 \mathrm{~s})$.

On September 8, 2018, the appearance of highfrequency (up to $1 \mathrm{~Hz}$ ) magnetic pulsations was recorded, which coincided in time with the emission increase in the recorded spectral ranges. Low-frequency (2-5 min periods) magnetic pulsations at 17:57:30 UT, which did not coincide with a burst of auroral intensity, were also observed. Approximately $2.5 \mathrm{~min}$ before the appearance of these low-frequency pulsations, an emission increase in the recorded spectral ranges was observed synchronously with the appearance of high-frequency magnetic pulsations.

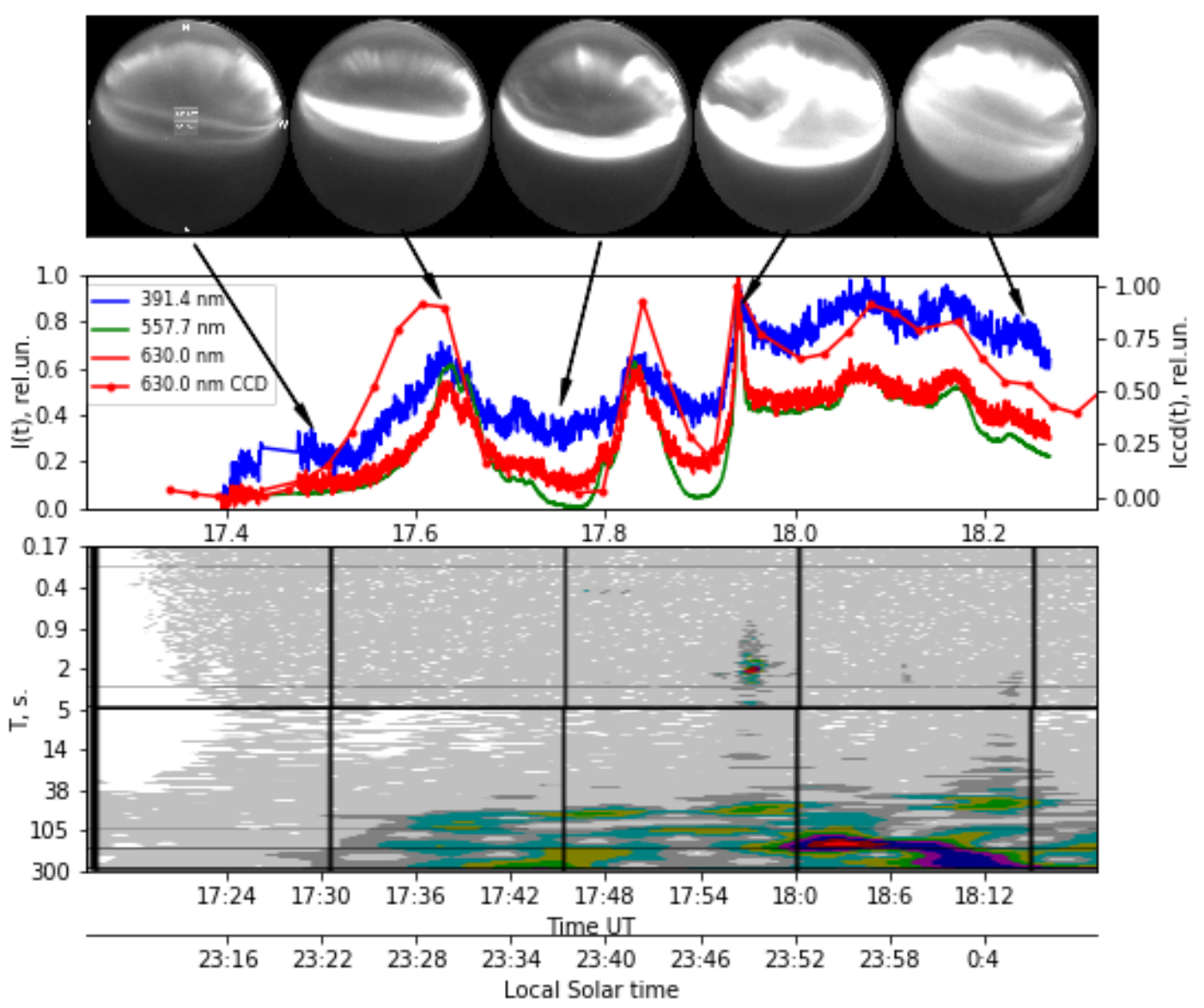

Figure 2. All-sky camera images in 630-nm emission, variations in 630-nm emission intensity from the camera in the northwest sector of the photometer field of view (NW, see Figure 1), and variations in the nightglow intensity within different spectral ranges from the photometer in the NW sector. The curves are shown against the background of the geomagnetic pulsations spectrum in the $0-300 \mathrm{~s}$. The camera's first frame shows the photometer's field of view 
During the next experimental campaign, the weather conditions enabled us to take measurements from November 29, 2018 to December 2, 2018. Note that this experiment was conducted during an interesting period: before the onset of the December 1, 2018 magnetospheric disturbance the geomagnetic field was very quiet for more than 3 days (November 28, 29, 30, 2018). The December 2018 magnetic disturbance began at $~ 13.30$ UT. Figure 3 shows i) $630-\mathrm{nm}$ emission intensity variations recorded using the photometer on December 1, 2018 ii) $\mathrm{H}$-component of the Norilsk magnetogram, and iii) variations in the 630-nm emission intensity from the all-sky camera in the photometer NW sector.
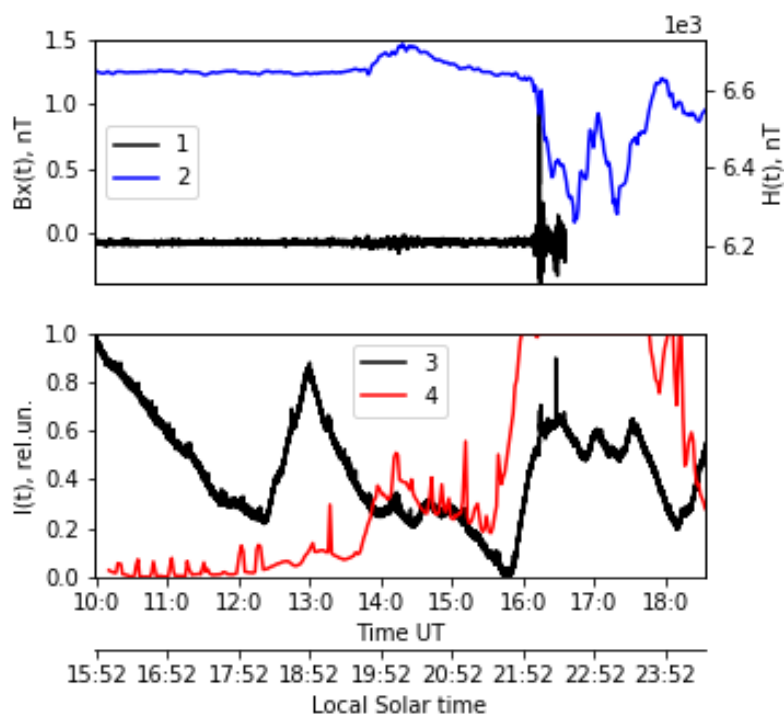

Figure 3. Variations of the $B_{x}$-component of the geomagnetic field from Lemi-30 (1), the H-component of the magnetic field at Norilsk (2), the $630 \mathrm{~nm}$ emission intensity variations from the photometer NW sector (3), and the $630 \mathrm{~nm}$ emission intensity variation from the camera (4) in the photometer NW sector 2018 December 1
Note that according to the all-sky camera data there was no local maximum recorded by all photometer channels at 13 UT. Similar unstable values of the photometer at sufficiently long time intervals are observed in other measurement sessions.

Geomagnetic pulsations occurred between 13.30 and 14.30 UT before the substorm active phase. The beginning of the substorm active phase at 16.10 UT was accompanied by a powerful surge of vibrations at the station Istok. The source was also traced from the ISTP SB RAS midlatitude station Mondy $\left(51^{\circ} \mathrm{N}, 100^{\circ} \mathrm{E}\right)$.

Figure 4 shows the time series of the $557.7 \mathrm{~nm}$ emission intensity with a remote trend (>20 min periods) obtained with the photometer and all-sky camera on December 1, 2018. In the time interval from 10 to 13 UT, the photometer and all-sky camera recorded pronounced variations in the $557.7 \mathrm{~nm}$ and $630 \mathrm{~nm}$ emission intensity with a period of $\sim 15 \mathrm{~min}$, probably of anthropogenic origin. At the same time, auroral pulsations were not followed by a magnetic disturbance (see Figure 3). Radiating structures in the $557.7 \mathrm{~nm}$ spectral channel and elongated structures with a length of the whole camera frame $\left(180^{\circ}\right)$ and a width $\sim 20-30^{\circ}$ of the field of view in the $557.7 \mathrm{~nm}$ and $630 \mathrm{~nm}$ spectral channels are visible on the camera frames. Images of these structures are shown in the frames $\operatorname{Im} 1$ and $\operatorname{Im} 4$ of Figure 4. Arrows indicate the moments of registration of the camera frame.

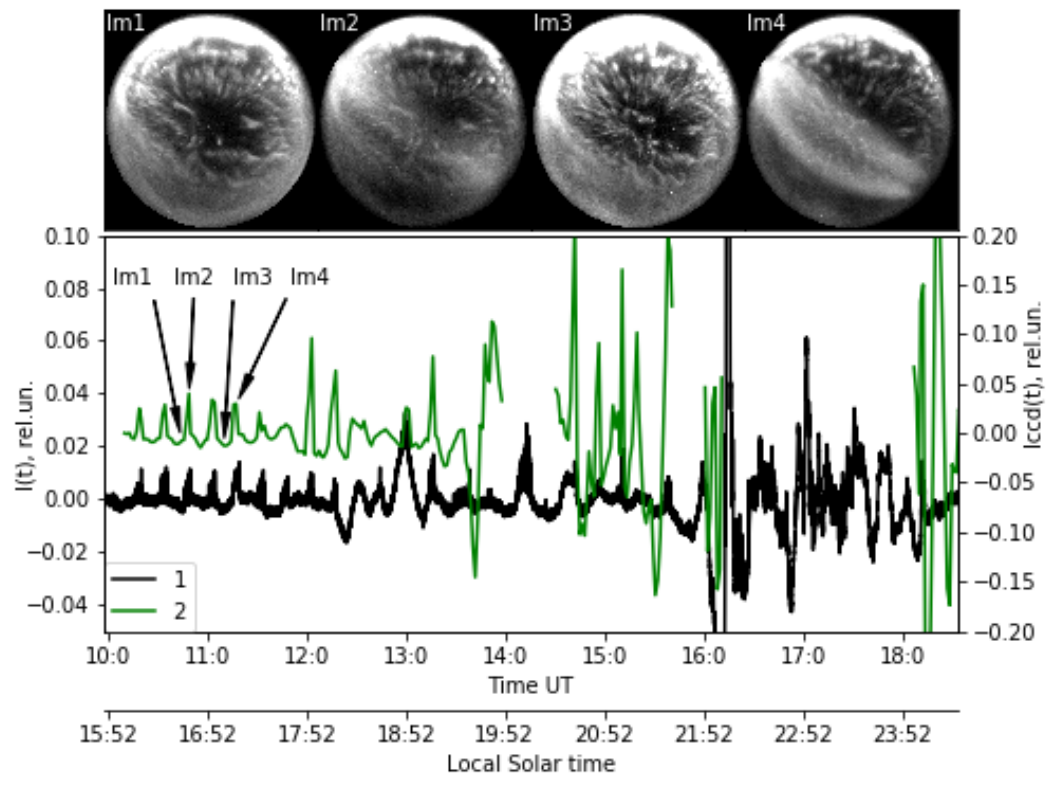

Figure 4. Camera frames of the all-sky camera in the $557.7 \mathrm{~nm}$ spectral range, the $557.7 \mathrm{~nm}$ emission intensity, from the photometer (1, axis to the left) and the all-sky camera (2, axis to the right) 2018 December 1 . Removed trend with periods longer than 20 min. Photometer and camera data are for the NW sector 

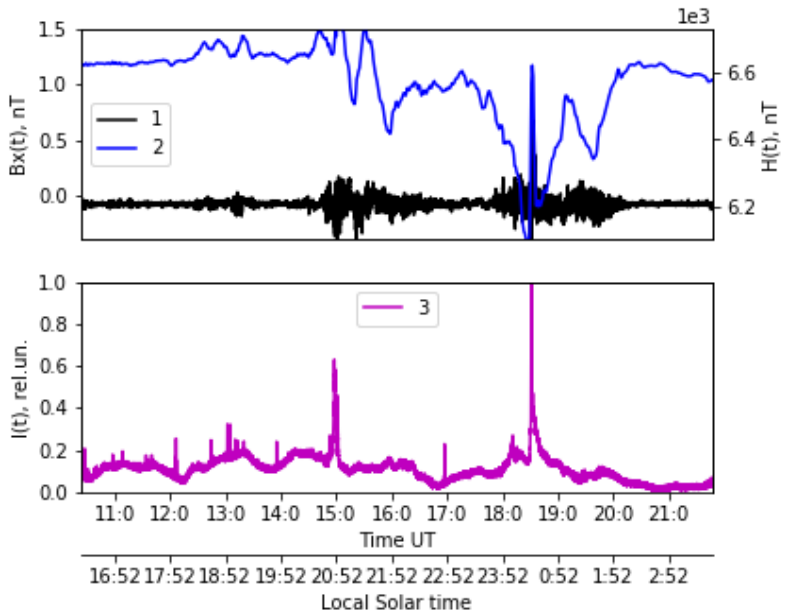

Figure 5. Variations of the $B_{x}$-component of the geomagnetic field from Lemi-30 (1), the magnetic field $\mathrm{H}$-component of Norilsk (2), and $391.4 \mathrm{~nm}$ emission intensity variations in the NW sector photometer (3) 2018 December 2

intensity variations recorded with the photometer on December 2, 2018, ii) the magnetic field H-component measured at Norilsk, and iii) a fragment of recording of geomagnetic pulsations. The appearance of synchronous auroral and geomagnetic variations can be seen.

\section{SHORT SIGNAL BURSTS IN PHOTOMETER DATA}

To search for optical flares, similar to those previously described in [Nadubovich, 1970; Kuzakova, 1972], the automatic processing of photometer data is performed, which allows us to select such events. At the same time, quite powerful signal bursts with $\sim 10 \mathrm{~ms}$ duration, probably of a hardware nature, are recorded simultaneously in all photometer channels. An example of such a signal is given in Figure 6.

Events with similar characteristics are also recorded during test measurements using a LED light source with a luminous intensity similar to the auroral luminosity during the experimental campaign at the station Istok. Test measurements have been carried out at the

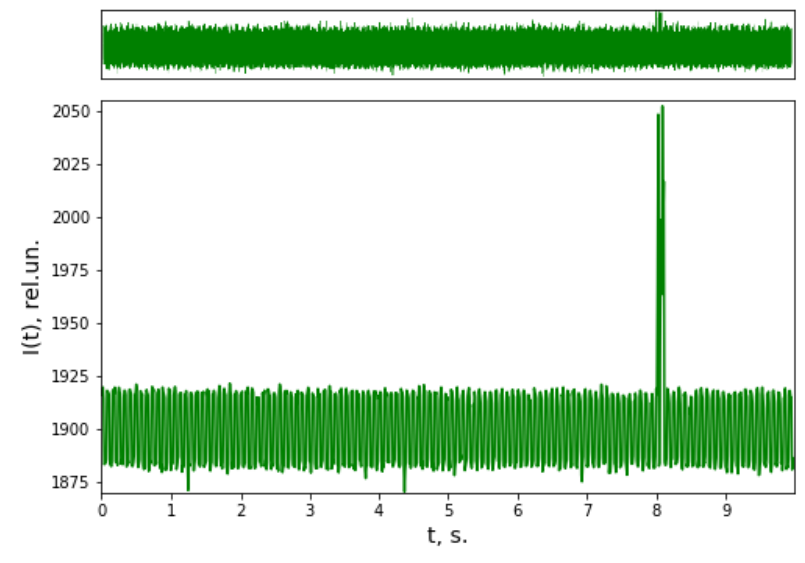

Figure 6. The signal surge in the $557.7 \mathrm{~nm}$ photometer channel, registered 2018 December 2 at 11:39:57 UT. The top panel is the raw data with a sampling frequency of $200 \mathrm{kHz}$. Bottom panel - summarized data with a sampling rate of $100 \mathrm{~Hz}$
ISTP SB RAS Geophysical Observatory (midlatitudes). In the test measurements no features were found in the time distribution of event registration. The recording frequency of such events during the test measurements was $\sim 1.3$ events/hour. Nevertheless, such signals recorded in auroral latitudes have a temporal distribution.

Figures 7 and 8 show the frequency distributions of bursts recorded with the photometer on December 1 and 2, 2018 respectively. In these Figures (red rectangles, left axis) is the number of recorded bursts at the $6 \mathrm{~min}$ interval. The burst frequency in these time intervals reaches 7 events on December 1, and 9 events on December 2. On September 8, 2018 with minor geomagnetic disturbances, the burst number in the 6 min interval reached 4. On magnetically quiet days on November 29 and 30, 2018, the burst occurrence frequency did not exceed 2 events per 6 min. Figures 7 and 8 indicate that the burst occurrence frequency increases immediately before geomagnetic disturbances and falls during strong disturbances. At the same time there is no clear correlation between the burst occurrence frequency and the level of the signal recorded at this time.

\section{CONCLUSION}

The photometer with silicon photomultipliers has shown itself quite well when recording short-period ( 20-min) auroral emission variations. In this case there is instability of the photometer signal level at sufficiently long time intervals. Such "floating" signals of this photometer were also recorded at the ISTP SB RAS Geophysical Observatory (GPO) $\left(51^{\circ} 48^{\prime} \mathrm{N}, 103^{\circ} 5^{\prime} \mathrm{E}\right)$. In addition, at present, the cause of the powerful signal bursts observed simultaneously in all photometer channels, which are likely to be associated with hardware effects, is not clear. In measurements at the station Istok, the burst occurrence frequency reaches 9 events
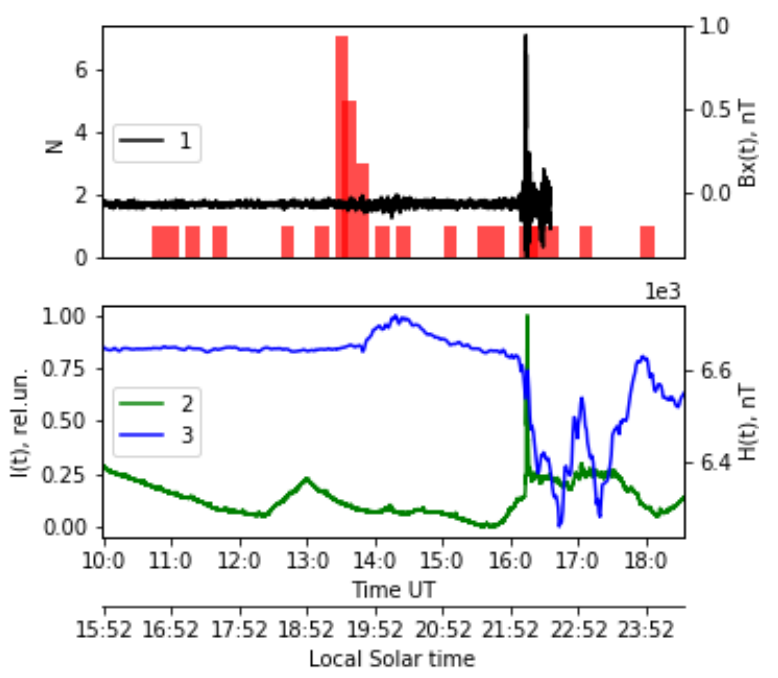

Figure 7. $B_{x}$-component variations of the geomagnetic field from Lemi-30 2018 December 1 (1), the burst signal recording frequency in $557.7 \mathrm{~nm}$ emission intensity from the photometer (red rectangles, axis on the left). Variations of the $557.7 \mathrm{~nm}$ emission intensity from the NW sector photometer (2) and the H-component of the magnetic field st. Norilsk (3) 


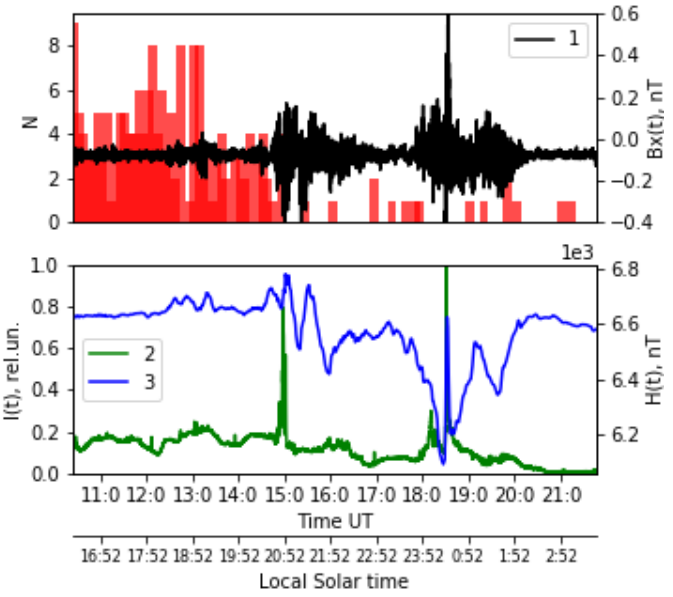

Figure 8. Fragment of analog recording of geomagnetic pulsations from Lemi-30 2018 December 2 (1), time distribution of the signal bursts number in 557. $\mathrm{nm}$ emission intensity from the photometer data (red bars, axis on the left). Variations of the $557.7 \mathrm{~nm}$ emission intensity in the sector NW 2018 December 2 from the photometer (2) and the H-component of the magnetic field (3) st. Norilsk

per $6 \mathrm{~min}$, i.e. 90 events/hr. The burst occurrence frequency in photometer signals increases immediately before geomagnetic disturbances and decreases during strong disturbances. At the same time there is no clear correlation between the burst occurrence frequency and the level of the signal recorded at that time. On magnetically quiet days, the frequency of optical flash occurrence does not exceed 2 events per $6 \mathrm{~min}$. In the test measurements at midlatitudes using a LED radiation source, the frequency of recording of such events is $\sim 1.3$ events/hr. At the same time, no features were found in the time distribution of event registration. It is worth noting that the conclusions on the signal bursts require further detailed study. Testing of equipment in laboratory conditions with the use of highly stable lowpower radiation sources, as well as additional series of experimental observations is required.

As a result of the first synchronous measurements of auroral and geomagnetic variations, synchronous bursts of auroras and geomagnetic pulsations were recorded at the station Istok with a high temporal resolution on September 8 and December 1-2, 2018. The appearance of high-frequency (up to $1 \mathrm{~Hz}$ ) geomagnetic pulsations coinciding in time with an emission increase in the recorded spectral ranges was observed.

We have demonstrated that it is possible to simultaneously record auroral and geomagnetic pulsations with high temporal resolution, using the photometer with radiation detectors based on silicon photomultipliers and the three-component induction magnetometer Lemi-30. This equipment can be launched in automatic monitoring mode, which will allow us to obtain a large array of data.

This work was supported by the RFBR grant No. $17-$ 05-00492.

The results were obtained using the equipment of Center for Common Use "Angara" [http://ckp-rf.ru/ckp/3056].

\section{REFERENCES}

Arnoldy R.L., Lynch K.A., Austin J.B., Kintner P.M. Energy and pitch angle-dispersed auroral electrons suggesting a time-variable, inverted-V potential structure. J. Geophys. Res. 1999, vol. 104, pp. 22,613-22,622.

Beach R., Cresswell G.R., Davis T.N., Hallinan T.J., Sweet L.R. Flickering, a 10-cps fluctuation within bright auroras. Planet. Space Sci. 1968, vol. 16, pp. 1525-1526.

Beletsky A.B., Tashchilin M.A., Mikhalev A.V., Tatarnikov A.V. Shamrock SR-303i airglow spectral measurements. Sovremennye problemy distantsionnogo zondirovaniya Zemli iz kosmosa [Modern problems of remote sensing of the Earth from space]. 2016, vol. 13, no. 3, pp. 192-197. (In Russian).

Berkey F.T., Silevitch M.B., Parsons N.R. Time sequence analysis of flickering auroras: 1. Application of Fourier analysis. J. Geophys. Res. 1980, vol. 85, pp. 6827-6843.

Campbell W.H. Rapid Auroral Luminosity Fluctuations and Geomagnetic Field Pulsations. J. Geophys. Res.: Space Phys. 1970, vol. 75, no. 31, pp. 6182-6208.

Ermilov S.Yu., Mikhalev A.V., Ermilov S.Yu., Mikhalev A.V. Fast Variations In Mid-latitude Sky Optical Radiation. Issledovaniya po geomagnetizmu, aeronomii i fizike Solntsa [Research on geomagnetism, aeronomy, and solar physics]. Moscow, Nauka, 1989, vol. 84, pp. 119-125. (In Russian).

Fukuda Y., Kataoka R., Uchida H.A., Miyoshi Y., Hampton D., Shiokawa K., Ebihara Y., Whiter D., Iwagami N., Seki K. First evidence of patchy flickering aurora modulated by multi-ion electromagnetic ion cyclotron waves, Geophys. Res. Lett. 2017, vol. 44, iss. 9, pp. 3963-3970. DOI: 10.1002/2017gl072956.

Korobtsova L.P. Characteristics of Optical Bursts Observed in Yakutsk. Neodnorodnosti v ionosfere [Irregularities in the ionosphere]. Yakutsk. YF SO AN SSSR. 1981, pp. 96102. (In Russian).

Kuzakova L.P. Short Bursts Of Integrated Radiation From Auroras. Geomagnetizm i aeronomiya [Geomagnetism and aeronomy]. 1972, vol. 12, no. 3, pp. 560-561. (In Russian).

McFadden J.P., Carlson C.W., Boehm M.H., Hallinan T.J. Field-aligned electron flux oscillations that produce flickering aurora. J. Geophys. Res. 1987, vol. 92, no. A10, pp. 11,13311,148 .

Nadubovich Yu.A. Outbreaks of 6300 and $5577 \AA$ in auroras. Geomagnetizm i aeronomiya [Geomagnetism and aeronomy]. 1970, vol. 10, no. 5, pp. 926-929. (In Russian).

Paulson K.V., Shepherd G.G. Short-lived brightness oscillations in active auroras. Can. J. Phys. 1966, vol. 44, pp. 921-924.

Richardson G. Energetic Particles and Corotating Interaction Regions in the Solar Wind. Space Sci. Rev. 2004, vol. 111, iss. 3-4, pp. 267-376. DOI: 10.1023/B:SPAC.0000032689.52830.3e.

Roldugin V.K., Roldugin A.V. Change Periodicity in the Rigidity of the Invading Electrons During Auroral Pi3 Pulsations. Geomagnetizm i aeronomiya [Geomagnetism and aeronomy]. 2017, vol. 57, no. 3, pp. 298-306. (In Russian).

Shiokawa K., Katoh Y., Hamaguchi Y., Yamamoto Y., Adachi T., Ozaki M., Oyama S.-I., Nosé M., et al. Groundbased instruments of the PWING project to investigate dynamics of the inner magnetosphere at subauroral latitudes as a part of the ERG-ground coordinated observation network. Earth, Planets and Space. 2017, vol. 69, iss. 1, article id. 160, 21 p. DOI: 10.1186/s40623-017-0745-9.

Tung Y.-K., Delory G.T., Carlson C.W. Modulation of auroral field-aligned electron fluxes under two inverted-V structures at different altitudes. Geophys. Res. Lett. 2002, 29(10), 1428, DOI: $10.1029 / 2001$ GL013719.

URL: http://sdnet.thayer.dartmouth.edu/aacgm/aacgm calc.php\#AACGM (accessed January 21, 2019).

URL: http://ckp-rf.ru/ckp/3056 (accessed January 21, 2019).

How to cite this article:

Beletskii A.B., Rakhmatulin R.A., Syrenova T.Ye., Vasilev R.V., Mikhalev A.V., Pashinin A.Yu., Shiokawa K., Nishitani N. Preliminary results of simultaneous recording of auroral and geomagnetic pulsations at the ISTP SB RAS station Istok. Solar-Terrestrial Physics. 2019. Vol. 5. Iss. 2. P. 39-44. DOI: $10.12737 / \mathrm{stp}-52201906$ 